\title{
Ciências, culturas e educação: reflexões acerca do "eu” e do "outro" em um processo formativo docente
}

Science, culture and education: reflections on the "Me" and the "other"

\author{
M. C. L. Brito ${ }^{1 *}$ Y. L. Jesus ${ }^{2}$; E. T. Lopes ${ }^{3}$ \\ ${ }^{1}$ Programa de Pós-Graduacção em Ensino de Ciências e Matemática, Universidade Federal de Sergipe, 49.100.000, \\ São Crostóvão-Sergipe, Brasil \\ ${ }^{2}$ Departamento de Biociências, Universidade Federal de Sergipe, Campus Porf ${ }^{\circ}$ Alberto Cavalho, 49.500.000, \\ Itabaiana-Sergipe, Brasil
}

${ }^{3}$ Programa de Pós-Graduacção em Ensino de Ciências e Matemática, Universidade Federal de Sergipe, 49.100.000, São Crostóvão-Sergipe, Brasil

*camilaquimicaufs@hotmail.com

(Recebido em 18 de outubro de 2015; aceito em 29 de outubro de 2016)

\begin{abstract}
Esta investigação foi desenvolvida junto às ações dos programas PIBID/ PRODOCÊNCIA/CAPES da área de Química/Ciências- UFS, do Campus Itabaiana. As ações de ensino, pesquisa e extensão desse subprojeto foram desenvolvidas em seis colégios estaduais sergipanos, durante os anos de 2012 a 2014. O objetivo deste trabalho é analisar, a partir dos contatos e convívio com uma comunidade quilombola, as reflexões de duas bolsistas pibidianas acerca do "eu" e do "outro". A perspectiva etnográfica e o relato autobiográfico constituem a metodologia do trabalho. Os métodos de coleta de dados foram o diário de campo e as observações. Assim, este trabalho possibilitou uma reflexão acerca das opiniões e visões das pesquisadoras/bolsistas sobre a cultura afro-brasileira, mais especificamente das visões acerca de "nós" e dos "outros", conforme exposto por Candau, buscando uma reflexão acerca da construção, histórica e culturalmente situada, da identidade docente.
\end{abstract}

Palavras-chave: Cultura 1, Educação 2, Identidade 3

This research was developed with the chemistry actions of PIBID/PRODOCÊNCIA/CAPES/Ciências-UFS programs, at Itabaiana Campus. Educational activities, research and extension of this subprojects were developed in six public schools from Sergipe during the years from 2012 to 2014. The objective of this study is to analyze, from contacts and socializing with a quilombo, the reflections of two fellows pibidianas of "me" and "other." The ethnographic perspective and the autobiographical are the methodology of this work. Data collection methods were field diary and notes. This work enabled a reflection on the opinions and views of the researchers / scholars on the african-Brazilian culture, specifically the visions about "we" and "others", as stated by Candau, looking for a reflection on the teaching identity construction, historically and culturally situated.

Keywords: Culture 1, Education 2, Identity 3

\section{INTRODUÇÃO}

A compreensão de que o ser humano é resultado do meio cultural é defendida por diversos pesquisadores, como Laraia (1986) [1] e Geertz (1989) [2]. Nesse sentido, o ser humano é resultado do meio cultural em que foi socializado; portanto herdeiro de um longo processo acumulativo, "que reflete o conhecimento e a experiência adquiridos pelas numerosas gerações que o antecederam [1, 4, 5]". Geertz (1986) [2, p. 4] assume o seguinte conceito de cultura como "sendo essas teias e a sua análise; portanto não como uma ciência experimental em busca de leis, mas como uma ciência interpretativa à procura do significado" [2, p. 4].

Desse entendimento pode-se inferir que a cultura condiciona o modo de o indivíduo ver o mundo e, consequentemente, ele (o indivíduo) tende a considerar a sua forma de vida como a mais certa e natural. Essa tendência [1], denominada etnocentrismo, em casos extremos é responsável pela ocorrência de diversos conflitos de cunho social. Assim, o modo como as pessoas agem, comem ou se vestem pode chocar algumas pessoas e ser natural para outras, e isso se relacionado com a cultura na qual o indivíduo está inserido. Nessa perspectiva, “[...] todos os homens são dotados do 
mesmo equipamento anatômico, mas a utilização do mesmo, ao invés de ser determinada geneticamente [...], depende de um aprendizado e este consiste na cópia de padrões que fazem parte da herança cultural do grupo." [1. p. 70 e 71]

Laraia (1986) [1. p. 52] ainda salienta que "[...] a comunicação é um processo cultural. Mais explicitamente, a linguagem humana é um produto da cultura, mas não existiria cultura se o homem não tivesse a possibilidade de desenvolver um sistema articulado de comunicação oral."

No que diz respeito à educação, Candau (2006) [3] nos coloca diante da necessidade de nos aprofundar na compreensão das relações entre educação e cultura(s). Nesse esteio, a autora [3] critica o caráter homogeneizador da escola e afirma que as questões culturais não podem ser ignoradas pelos/as educadores/as devido ao multiculturalismo presente em sala de aula. A autora ainda defende a importância do papel da educação e das diferentes formas de comunicação entre os membros da sociedade, propondo a perspectiva do/a professor/a como agente cultural [3]. Assim, a compreensão das relações entre educação e cultura/s se refere "[...] a uma concepção diferente da escola como um espaço de cruzamento de culturas, fluido e complexo, atravessado por tensões e conflitos." [3, p. 40, grifo da autora]. No entanto, a maioria dos cursos de formação de professores não contempla essas discussões (LOPES, BRITO e JESUS, 2013) [4].

Assim, é possível observar que os cursos de licenciatura de Ciências da Natureza não fogem da realidade apresentada por Candau (2006) [3]. É possível constatar isso, por exemplo, nos Projetos Políticos Pedagógicos (PPP) das licenciaturas de Ciências Biológicas, de Física, de Química e de Matemática do Campus Professor Alberto Carvalho da UFS, que não contemplam as relações entre educação e cultura(s) [6]. Ainda nesse sentido, esses cursos não abordam as relações entre ciências e cultura, ou em outras palavras, as diferentes dimensões da cultura (LOPES, 2012) [5].

Nessa perspectiva, relacionando com os apontamentos de Candau (2006) [3], são pertinentes as reflexões de Carvalho e Gil-Pérez (1998) [6] e Chassot [7, 8] no que diz respeito aos objetivos e à formação do professor de Ciências Naturais. Assim, a respeito da formação dos professores de Ciências registra-se a importância das necessidades formativas apontadas por Carvalho e Gil-Pérez, (1998) [4] que podem ser resumidas na relação entre o "saber" e o "saber fazer".

Nesse esteio, além das necessidades formativas apresentadas [4], destacam-se as reflexões de Candau (2006) [3, p. 40], que consideram o/a professor/a como agente cultural e critica a "[...] consciência do caráter monocultural da escola [...]" e defende a "[...] necessidade de romper com ela e construir práticas educativas em que a questão da diferença e do multiculturalismo se faça cada vez mais presente"

Dessarte, apresentam-se alguns elementos na perspectiva da reinvenção da escola, tais como: "reconhecer nossas identidades culturais", "identificar nossas representações dos "outros"” e "conceber a prática pedagógica como um processo de negociação cultural” [3]. Por conseguinte, é necessário questionar o pouco entendimento e acesso durante os processos formativos docentes ao conceito de cultura(s). Realidade que não contribui, também, para a formação dos professores de Ciências, partindo do entendimento deste também como agente cultural.

Por sua vez, Chassot (2001) [7] critica a realidade do ensino de Ciências na contemporaneidade e propõe interpretar criticamente a Ciência como uma produção do ser humano e uma das diversas formas de ler e compreender o mundo, logo "uma linguagem para facilitar nossa leitura do mundo" [7]. Para o autor, é necessário conhecer e compreender a história da produção dos conhecimentos científicos, além de verificar as contribuições dos africanos, dos indígenas e das mulheres na construção do conhecimento científico. A Ciência é considerada pelo autor como uma linguagem construída pelos homens e mulheres de forma a ilustrar o mundo natural e, desse entendimento, compreender a linguagem das Ciências é como compreender uma outra linguagem, ou seja, adentrar a uma outra dimensão da cultura $[6,7]$.

Esses pressupostos fundamentaram as ações no âmbito do subprojeto Química-Campus Itabaiana, da Universidade Federal de Sergipe, dos programas PIBID-CAPES e PRODOCÊNCIACAPES. Neste trabalho apresentaremos as atividades realizadas junto a uma realidade escolar quilombola, visando produzir conhecimentos, a partir do entendimento do professor como agente cultural e da Ciência como uma linguagem utilizada para explicar o mundo natural, acerca da construção da identidade docente. Sintetizamos, assim, os objetivos deste trabalho: analisar, a partir dos contatos e convívio com uma comunidade quilombola, as reflexões de duas bolsistas pibidianas acerca do "eu" e do "outro". 


\section{MATERIAL E MÉTODOS}

O presente trabalho tem como abordagem a pesquisa qualitativa, pois tem como característica o contato direto e intensivo com o estudo a ser realizado e visa abordar o mundo "lá fora", descrever e, às vezes, explicar os fenômenos sociais "de dentro" de diversas maneiras [10]. Adotamos o caráter etnográfico e o relato (auto)biográfico. O primeiro, pelo fato de a investigação consistir numa "descrição profunda", na interpretação da vida e do senso comum [11]. O segundo, por surgir a partir do enraizamento no curso da vida, de forma que representamos a nossa existência e como contamos para nós mesmos e para os outros, em estreita relação com a história e a cultura [12].

Neste trabalho destacaremos as atividades desenvolvidas por duas bolsistas pibidianas ${ }^{1}$ (B1 e B2), no âmbito do contexto formativo docente do PIBID e PRODOCÊNCIA, durante os anos de 2013 e 2014, na Escola Quilombola 27 de Maio I, no povoado Mocambo. B1 cursava a Licenciatura em Química², e B2 é acadêmica do curso de Licenciatura em Ciências Biológicas ${ }^{3}$.

O povoado Mocambo é um quilombo localizado em Porto da Folha, no estado de Sergipe, fronteira com Alagoas, distante $150 \mathrm{~km}$ do litoral sergipano. Essa é a primeira comunidade negra do estado que foi reconhecida pelo Governo Federal, através da Fundação Cultural Palmares, em 1997. A titulação de posse dos 2.100 hectares de terras aconteceu no dia 14 de julho de 2000 [12].

As instituições existentes na comunidade Mocambo compreendem uma associação da comunidade quilombola, um clube social, uma fábrica de queijo, uma mercearia, uma pousada, uma igreja e uma escola com dois prédios em locais diferentes. $\mathrm{O}$ abastecimento de água somente foi implantado em 2006 pela Companhia de Saneamento de Sergipe (DESO), e a energia elétrica é fornecida pela Energisa (Distribuidora de Energia em Sergipe).

Atualmente, as ruas são calçadas e sem rede sanitária. O sistema de coleta de lixo foi inserido após a realização de uma oficina de mobilização social, visto que antes o lixo domiciliar era colocado a céu aberto, ou seja, às margens do rio, nos quintais, queimando ou enterrando [10].

As principais fontes de renda consistem na confecção de artesanato e da prática da agricultura de alimentos, como feijão, milho, mandioca, batata; da pesca; criação de animais, como suínos, bovinos e caprinos. Esses produtos, além de manter as necessidades da comunidade, são comercializados nas feiras das cidades vizinhas.

As escolas nessa comunidade ofertam o Ensino Fundamental (Escola Estadual 27 de Maio I) e o Ensino Médio (Escola Estadual 27 de Maio II) e atendem alunos tanto da comunidade quilombola quanto alunos não quilombolas moradores de povoados vizinhos.

A coleta de dados foi realizada por meio do registro nos Cadernos de Campo de duas bolsistas, nos quais constavam suas visões, reflexões e observações. Nesses cadernos de campo encontramse, também, dados das conversas informais com os professores, alunos e alguns membros da comunidade.

O caderno de campo foi elaborado desde o início das atividades das bolsistas. Este foi organizado em duas partes. Na primeira parte constavam anotações sobre as reflexões acerca da identidade cultural das bolsistas, sua ancestralidade/origem. A segunda, consistiu no registro das concepções acerca da comunidade quilombola e das observações e reflexões antes, durante e após a visita à escola na comunidade supracitada. Assim, esses cadernos de campo constituíram-se em diários pessoais que possibilitam as investigadoras acompanhar o desenvolvimento das observações, visões e reflexões das bolsistas.

Apresentaremos no próximo tópico, a partir dos registros nesses cadernos de campo, as visões acerca das identidades culturais e das visões acerca do "outro", manifestadas e refletidas pelas bolsistas.

\section{RESULTADOS E DISCUSSÃO}

Apresentaremos a seguir as visões e reflexões das bolsitas pibidianas (B1 e B2) acerca do "eu" e do "outro".

\footnotetext{
${ }^{1}$ Autoras deste trabalho.

${ }^{2}$ Atualmente mestranda do PPGECIMA-UFS e professora da rede estadual sergipana.

${ }^{3}$ Atualmente bolsista de Iniciação Científica - CNPq
} 


\section{Visões e reflexões acerca do "eu"}

A B1 colocou em seu Caderno de Campo que, a partir das reflexões acerca dos elementos propostos por Candau (2006) [3], para a reinvenção da escola há a necessidade do reconhecimento da própria cultura, ou seja, reconhecer a nossa identidade cultural (nossa origem). Assim, B1, a partir dos estudos teóricos realizados, fez uma reflexão do "eu" com o intuito de entender sua identidade cultural e registra que, através de conversas com os familiares, pode-se descobrir que "somos descendentes de negros, de índios, de brancos, entre outros".

Assim, em seus registros B1 destacou que sempre teve curiosidade em entender sua origem e foi assim que começou a conversar com seu pai, o qual lhe disse que era bisneto de uma Sinhá (branca) bastante respeitada na região, cujo esposo era holandês.

Os estudos durante o período que foi bolsista do PIBID trouxeram algumas indagações. A primeira, diz respeito ao fato de ser morena, do cabelo crespo, contudo, segundo relato de seu pai, tataraneta de uma Sinhá branca e dos cabelos lisos. Essas diferenças eram motivos de brincadeiras na família. No entanto, relata que não se sentiu discriminada pela família, mas incorporou, pelas questões familiares e pela cultura da cidade onde mora, a opção por alisar o cabelo. B1 descreveu que não conseguiu identificar a origem dessas características, a exemplo do cabelo crespo, pois os familiares com os quais convive são brancos com cabelos lisos e olhos claros.

B1 ainda argumentou, a partir da questão acerca de "quem sou eu", que, quando estudou a "Escravidão no Brasil", na disciplina de História, no Ensino Fundamental, ficou chocada com as iniquidades que faziam com os negros e índios, mas "não passou por minha cabeça se esses escravizados eram meus parentes". A partir do exposto, B1 considerou que há ascendência africana em sua família e aponta que esse fato demanda mais estudo sobre o assunto.

A bolsista ainda refletiu: "Mas, qual a importância de descobrir isso?". Respondeu em suas anotações: "Quando temos curiosidade de saber a nossa origem, passamos a melhor entender o nosso papel na sociedade". Assim, concordando com os teóricos estudados, argumentou que as reflexões sobre a própria identidade cultural podem facilitar na concepção de vários assuntos que são abordados na sociedade, com ênfase na escola. Utilizando desses teóricos, acrescentou que o modo de ver o mundo "[...] os diferentes comportamentos sociais e mesmo as posturas corporais são assim produtos de uma herança, ou seja, o resultado da operação de uma determinada cultura" [1].

Nesse sentido, Laraia (1986) [1] considera que o homem faz uma busca dos esclarecimentos para os fatos cruciais, como a vida e a morte, na tentativa de explanar o início e o fim da vida humana. Sendo assim,

[...] Explicar a vida implica a compreensão dos fenômenos da concepção do nascimento. Estes são importantes para a ordem social. Da explicação que o grupo aceita para a reprodução humana resulta o sistema de parentesco, que vai regulamentar todo o comportamento social (LARAIA, 1986, p.89). [1]

A Bolsista 2, por sua vez, registrou que, com o intuito de identificar e reconhecer as "nossas identidades culturais", foi necessário refletir a respeito do "eu". Assim, a partir dessas indagações, refletiu sobre os seguintes questionamentos: Quem sou? Qual a minha origem? Qual a minha ascendência? Será que é indígena, negra, branca (portuguesa, espanhola, francesa, entre outras)?

Recordou dos filmes, reportagens, aulas e livros que mostram a formação do povo brasileiro, a chegada dos portugueses, dos demais europeus e dos povos africanos ao Brasil, da escravidão indígena e negra. Imaginou-me naquele período, com seus familiares naquele momento histórico e começou a questionar a respeito de sua herança cultural, da sua identidade cultural: "Se eu pertencesse àquele período, de qual grupo eu faria parte? Seria o dos nativos (os indígenas), dos colonizadores (os europeus) ou dos trazidos à força para essa terra (os africanos)?". Considerou que é complexo saber, exatamente, a qual grupo desses pertencemos, pois o Brasil apresenta uma diversidade cultural enorme, que apresenta uma mistura de povos, diversos grupos étnico-raciais e, portanto, diferentes culturas. Nesse contexto, registrou em seu caderno, a partir dos estudos realizados como bolsista, que a diversidade étnico-racial brasileira é "[...] um fato inegável 
evidenciado ao olharmos para os espaços sociais brasileiros, realidade ratificada nos debates e produções acadêmicas que têm se ampliado nas últimas décadas [...]" [15].

A partir da necessidade de se conhecer sua identidade cultural, sua origem, procurou, em conversas informais com seus familiares, reviver o passado com o intuito de identificar a sua origem. Além disso, considerou que quando conhecemos o "eu" é mais propício de se aceitar o "outro", melhorando o relacionamento entre estes no âmbito social.

Assim, na procura de saciar sua curiosidade e inquietação a respeito da própria origem, enquanto conversava com seu pai, identificou que ele é bisneto de uma índia (presença de poucos pelos, com pele, cabelo e olhos mais escuros e com olhos pequenos e puxados) que casou com um branco (pele, olhos e cabelos claros), por isso as características físicas são próximas das dos indígenas.

Na família de sua mãe identificou a ascendência negra e indígena, sendo que as características e traços físicos mais presentes são os da ascendência negra, afro-brasileira. Segundo a bolsista, a origem de sua família é constituída a partir da descendência desses diferentes grupos étnicos. Ressaltou que "esses foram os que identifiquei, mas quantos outros não devem ter constituído minha família de geração para geração?".

A bolsista evidencia que, como coloca Lopes et al. (2012) [15], durante a história da humanidade "sempre estivemos em contato com sociedades e mundos diferentes", nunca vivemos numa situação absolutamente isolada, como é mostrada na escola, pois essa possibilidade é praticamente inexistente.

Concluiu que tem ascendência indígena, negra e branca, como a maioria dos brasileiros, apresentando alguns hábitos e costumes das etnias indígenas e das africanas, como o uso de algumas ervas para fins medicinais, costume de dormir em rede, alimentar-se com alimentos como milho, macaxeira, amendoim, feijoada, farinha, peixes, entre outros. Também identificou por parte da família materna e paterna a tradição de benzer, por exemplo, contra o "mau olhado".

Constatamos que as bolsistas, ao abordar e refletir seu "eu", de maneira distinta, marcaram suas reflexões nas características fenotípicas, destacando os registros de B1, que sintetizou seus registros no que diz respeito às marcas raciais com presença afrodescendente. Por sua vez, as reflexões de B2 foram recheadas pelas características físicas e pelas possíveis heranças culturais. Tal abordagem com privilégio de características físicas pode ter relação com o "preconceito de marca" apontado na realidade brasileira, que indica a prevalência de marcas no corpo como reprodutoras das desigualdades. Outra hipótese é que tenha relação com a forma pela qual os estudos no grupo podem ter sido conduzidos, visto que podem ter sido privilegiadas as questões fenotípicas em detrimento das questões étnicas. Essas novas hipóteses poderão ser respondidas na continuidade da investigação.

\section{Reflexões acerca do "outro"}

Refletimos no tópico anterior as visões das bolsistas acerca da própria identidade cultural. Neste tópico apresentamos as visões e reflexões das bolsistas B1 e B2 acerca do "outro", daquele que consideramos diferentes [3]. Neste trabalho o "outro" refere-se à comunidade quilombola, na qual as bolsistas desenvolveram os trabalhos.

\section{Visões e reflexões de B1}

B1, ao se referir as suas concepções acerca da comunidade quilombola, relembra das aulas de história do Ensino Fundamental, quando estudava o processo de formação dos quilombos. Assim, sua visão era de que o quilombo seria um "lugar escondido, pois esses locais eram os refúgios dos escravos "fujões". Acrescenta que "achava que as casas eram de barro e cobertas de palhas de bananeiras, com terreiro para seus rituais religiosos e para as crianças brincarem, localizando próximos de rio ou riacho para o próprio consumo" (B1, 2013). A bolsista ainda acrescenta que sobre o modo de se vestir

[...] minha visão era que as mulheres usavam saias brancas, longas e rodadas com blusas de mangas gastadas de tanto seus filhos puxarem para se amamentarem. Além disso, achava que a maioria usasse lenço na cabeça, com a 
intenção de levar os potes ou baldes de água para consumo. Já os homens usavam umas calças remendadas e compridas com um cinto feito de corda, sem camisa e chinelos de couro (B1, 2014).

Com relação à religião $\mathrm{B} 1$, imaginava que se baseava no candomblé, na umbanda, com a presença de santos/orixás, como Iemanjá. Acrescenta ainda que "outro feitio presente em nossa sociedade e de origem africana é a capoeira, considerada um esporte hoje em dia, mas antes era o meio que os escravos encontravam para se defender dos capitães do mato ou invasores".

Para B1, a primeira visita à comunidade quilombola foi marcada de muitas aventuras. A bolsista destaca inicialmente o difícil acesso a essa comunidade, pois, em sua opinião, "fica longe da Universidade, a aproximadamente $150 \mathrm{~km}$ ". Contudo, para a bolsista, a curiosidade e ansiedade fizeram com que a viagem fosse bem rápida. A primeira impressão que teve, quando estava se aproximando do local, foi "que não tinha como existir pessoas no meio daquele mato". Mas quando se aproximou "comecei a ver algumas casas, adolescentes ouvindo músicas em um carro na beira do rio (o famoso Rio São Francisco). Esse rio é lindo, extenso, com uma mistura de cores verde e azul". Assim, ao percorrer o povoado, começou a fazer anotações das casas, das crianças brincando na rua e das donas de casa nas calçadas conversando. Anota em seu caderno:

As casas são feitas de alvenaria, a maioria rebocada e pintada, e cobertas por telhas, somente os muros dos quintais que são feitos de madeira e prego. As ruas são calçadas, mas sem rede de esgotos. Ao chegar próximo do colégio, tinha um terreno baldio, local onde os moradores jogam futebol nos finais de semana (B1, 2014).

A respeito do modo de se vestir, observou duas mulheres que estavam sentadas na calçada, uma delas estava alimentando seu filho:

[...] ambas usavam shorts jeans com blusas de alças e coloridas. Além disso, elas estavam com os cabelos amarrados, devido ao calor. Já alguns homens e adolescentes estavam usando também short jeans com blusas regatas e de chinelos de plástico, a exemplo de havaianas (B1, 2014).

Ao caminhar pela rua principal do povoado, a bolsista registra a presença de carros, motos e bicicletas, "os quais são meios de transporte utilizados pelos moradores, inclusive as bicicletas são muito usadas pelos adolescentes para ir à escola". Além disso, próximo ao colégio estava um senhor "ajeitando seu 'carro de boi', transportando alimentos para seu gado".

Em relação à religião, foi registrada, na rua principal, a imagem de um santo católico, Padre Cícero, o qual era o padroeiro da comunidade. Aponta que, em conversas com professores e alunos, foi informado que a maioria dos moradores são católicos. Somente uma jovem disse em uma conversa informal que há nessa comunidade práticas que podemos identificar como originárias de religiões de matriz africana. Assinala que, com os dados coletados, até o momento, não é possível fazer alguma afirmação a respeito.

A partir de suas observações e registro, reflete que foi possível perceber que a maioria de suas concepções eram equivocadas. E, utilizando de Laraia (1986) [1], afirma que 'a cultura é dinâmica', ou seja, qualquer sistema cultural está em um processo consecutivo de modificação. Com efeito,

[...] os quilombolas não vivem como no tempo da escravidão, quando formaram os quilombos. Os quilombos e os sujeitos quilombolas mudaram, pois a cultura não é estática, e sim está em constante transformação, adquirindo novas aparências, costumes, valores a si mesma, possibilitando novas mudanças ao longo do tempo (B1, 2014).

As concepções manifestadas podem ter influência da escola, sobretudo pelo livro didático e também pela mídia, os quais podem apresentar uma visão estática, e muitas vezes estereotipada, de cultura [6]. Desse modo, "na sociedade em que vivemos há uma dinâmica de construção de 
situações de apartação social e cultural que confirmam os diferentes grupos socioculturais em espaços diferenciados, onde somente os considerados iguais têm acesso" [3].

Constata que, a partir das observações realizadas, passou a conhecer um pouco mais desse grupo cultural, entender um pouco de sua cultura, pois, [3] junto ao reconhecimento da própria identidade cultural, devemos relacionar as representações que construímos sobre os outros (aqueles que consideramos diferentes). Dessa forma, informados por estereótipos, se não estivermos atentos, podemos manifestar, por palavras e gestos, discriminação, desrespeito, desqualificação. Estes julgamentos decorrem de preconceitos, e pessoas negras têm sido vítimas deles. Não poucas vezes se ouve que pessoas "desta raça", os negros, são feios, sujos, violentos ou preguiçosos. Cabe mencionar aqui que a palavra raça não se refere ao conceito biológico de raças humanas, amplamente rechaçado pelos conhecimentos científicos aceitos nos dias de hoje [13].

Por fim, concordamos com as reflexões de B1, ao afirmar que suas visões tinham influência do que a mídia ou até mesmo os livros didáticos abordavam sobre essas culturas, como, por exemplo, a escravidão como tema principal.

\section{Visões e reflexões de B2}

B2 inicia suas anotações relatando que quando soube que iria trabalhar com uma comunidade quilombola, logo imaginou os quilombos como relatados em livros de história e apresentados em filmes que trabalham temas como a escravidão no Brasil. Assim, a expectativa inicial para essa comunidade, ao pensar em Quilombos, era de encontrar algo bem distinto da nossa realidade e próximo do período em que surgiram os quilombos, com a fuga dos negros, ditos "negros fujões", das senzalas das fazendas, se embreando na mata (longe das cidades e das fazendas, distante de todos, em locais precários, com o mínimo de estrutura para se viver) e sobrevivendo do que conseguissem plantar e caçar.

Embora soubesse que não estaria, exatamente, como na época da escravidão, acreditava que manteriam alguns costumes e tradições da época e que sua localização seria relativamente distante das cidades mais próximas. Além disso, imaginou que mantivessem suas crenças e religiões de matrizes africanas, como o Candomblé, além de "rituais de luta como a capoeira, hoje tida como um tipo de esporte".

Desse modo, B2, ao se aproximar da comunidade, percebeu sua distância com outras localidades e sua beleza por ficar às margens do Rio São Francisco. B2 registra que começou "a imaginar as relações que essa comunidade mantinha com esse rio", tanto do ponto de vista do seu sustento alimentar, como dos rituais relacionados à cultura e religiões de matrizes africanas, "passadas por nossos antepassados durante gerações".

Mas, assinala certo "estranhamento", ao constatar diferenças entre o que imaginou e o que observou. Inicialmente, porque a comunidade se assemelha a uma pequena vila, em que as casas apresentam uma estrutura básica, semelhante as casas encontradas em muitos povoados, não quilombolas. Ao caminhar pela comunidade, percebeu que seus membros apresentavam dependência com a pequena agricultura e com a pesca no rio. Além disso, algo despertou sua atenção e provocou inquietação:

[...] logo na entrada da comunidade, em frente a uma casa, havia uma imagem, grande (dentro de um tipo de oratório de madeira e vidro) de Padre Cícero, um santo da religião Católica, padroeiro da comunidade. Essas são evidências da presença da religião católica, embora possa haver outras religiões de matrizes africanas, menos seguidas, como relatado em conversas informais com alguns alunos da escola quilombola, moradores da comunidade investigada (B2, 2013).

Em conversas informais mantidas por B2, com alunos e moradores dessa comunidade, durante as idas à própria comunidade, a bolsista aponta em seus registros que "praticam a capoeira, com menos frequência, e que há vaquejadas".

Em algumas das visitas de B2 nessa comunidade, foram realizadas conversas com membros mais antigos. Sobre isso, a bolsista, em alusão a Candau [3], considera que 
[...] nessas conversas relataram sobre a formação da comunidade Mocambo e lutas pela terra. Assim, foi possível conhecer um pouco mais sobre a história dessa comunidade e contribuir para a transformação de nossas concepções e visões iniciais, necessárias ao professor que atua enquanto agente cultural, em busca de relações mais positivas em meio à diversidade da sala de aula (B2, 2013).

Assim, B2 infere que, após a visita à comunidade, notou que

[...] muitos de nós bolsistas e voluntários tínhamos uma visão distorcida do que seria uma comunidade quilombola. Acreditávamos que essa comunidade estaria parada no tempo sem qualquer interação com a vida urbana, conservando seu modo de vida sem alteração durante todo o tempo (B2, 2013 e 2014).

Com efeito, Laraia (1986) [1] afirma que 'a cultura é dinâmica', ou seja, qualquer sistema cultural está em um processo consecutivo de modificação. As visões do diferente como inferior colocado enquanto 'menos evoluído', assim, grande parte das comunidades que vivem em um determinado contexto sociocultural apresentam uma visão etnocêntrica no que diz respeito a diferentes culturas, colocando a sua cultura como superior e mais aceita [1].

A B2 relata ainda que, a partir de leituras e debates com o grupo de estudos acerca do conceito de cultura, tinham também certa dificuldade em compreender o que seria/m cultura/s, uma vez que não há um conceito exato, e sua relação com os indivíduos participantes dela. Assim, foi possível entender que cultura não é um processo estático, mas que está em constante transformação, incorporando novos aspectos culturais e apresentando transformações ao longo do tempo. Essas mudanças podem ser por fatores externos e internos, mas sempre está a cultura em processo de mudança, pois ela é dinâmica $[1,2]$.

Assim, percebemos que as bolsistas apresentaram uma visão estereotipada dos quilombos, difundida pelos livros didáticos e pela mídia. Contudo, após as leituras, convivência na comunidade e discussões no grupo de estudos, a B2 relata que suas visões caminharam no sentido do entendimento de que cada povo possui suas próprias crenças e costumes; não há uma hierarquia entre elas, mas sim diversas formas e perspectivas de ver e explicar o mundo, e diferentes explicações acerca das relações 'homem- natureza'. Com efeito, as bolsistas afirmam que:

Este trabalho possibilitou uma reflexão acerca de nossas opiniões em relação às diversas culturas, ou seja, das nossas visões acerca de "nós" e dos “outros", nos proporcionando uma compreensão mais ampla da construção de nossa identidade docente. Dessa forma, refletindo, também, a formação docente para a diversidade presente em sala de aula. Assim, temos um grande desafio pela frente no sentindo de aprimorar nossos conhecimentos sobre as diferentes dimensões da Cultura, como a Ciência. (JESUS, BRITO e LOPES, 2015, p. 13) [14]

\section{CONCLUSÃO}

Constatamos que as reflexões do "eu" instigaram as bolsistas a procurarem conhecer e compreender suas origens. Suas reflexões foram marcadas pelas características físicas, mas também caminharam, a exemplo de B2, para as características étnicas.

Sobre as visões do "outro", a comunidade quilombola, as bolsistas afirmaram que as visões e concepções mudaram ao conhecer a comunidade, possibilitando uma transformação nos seus "préconceitos" no momento em que conviveram com membros dessa comunidade e também com os estudos realizados.

Com essa investigação foi possível problematizar a necessidade e as possibilidades de se trabalhar na formação inicial docente com as diferentes culturas dos licenciandos ("eu") e suas visões acerca do "outro". Nesse caso, o "outro" é constituído como um grupo cultural diferenciado, elencado nesse trabalho como uma comunidade quilombola e seus moradores. 
Essas reflexões e experiências podem contribuir, num primeiro momento, para a (trans) formação das visões acerca dos "outros". Num segundo, para a identificação dos preconceitos e estereótipos acerca do "outro". Por fim, possibilita a (re/des) construção da identidade docente na perspectiva do professor enquanto agente cultural, conforme defendido nesta investigação (LOPES e JESUS, 2015) [15].

Desse modo, defendemos a necessidade de trazer para a sala de aula as contribuições dos diversos povos para a cultura brasileira, aos moldes do que preconiza a Lei 11.645/2008; e, no caso específico das Ciências da Natureza, reside também o desafio de estudar a contribuição desses povos na construção dos conhecimentos sobre a natureza. Posto esse desafio, acrescenta-se, por consequência, o convite para a construção de um ensino que respeite e considere a diversidade cultural brasileira.

\section{AGRADECIMENTOS}

\section{À CAPES e à FAPITEC-SE.}

\section{REFERÊNCIAS BIBLIOGRÁFICAS}

1. Laraia RB. Cultura um conceito antropológico. Rio de Janeiro: Ed. Zahar; 1986.

2. Geertz C. A interpretação das culturas. Rio de janeiro: LCT Editora; 1989.

3. Candau VM. O/A educador/a como agente cultural. In: Lopes ARC, Macedo EF, Alves MPC. (Orgs.). Cultura e política de currículo. Araquara-SP: Junqueira \& Marin; 2006, p. 35-52.

4. Lopes ET, Brito MCL, Jesus YL. Escola indígena na formação docente: uma experiência no PIBID. In: Anais $21^{\circ}$ Seminário de Educação 09-13 set 2013, Cuiabá, Brasil, Cuiabá: Educação e (des)colonialidades dos saberes, práticas e poderes; 2013. p. 340-141

5. Lopes, E. T. Conhecimento Bakairi Cotidianos e Conhecimentos Químicos Escolares: Perspectivas e Desafios. São Cristóvão - Se, 2012. Tese (Núcleo De Pós Graduação Em Educação) Universidade Federal De Sergipe.

6. Perez DG, Carvalho AMP. Formação de Professores de Ciências. (Tradução Sandra Valenzuela). São Paulo: Ed. Cortez; 1998.

7. Chassot A. Alfabetização Científica e Cidadania. In: Chassot A. Alfabetização Científica: questões e desafios para a educação. (Coleção educação em química). Ijuí: Ed. UNIJUÍ; 2001. 440 p.

8. Chassot A. Alfabetização científica: uma possibilidade para a inclusão social, Rev Brasileira de Educação. $2003 \mathrm{Jan} / \mathrm{Fev} / \mathrm{Mar} / \mathrm{Abr} ;$ (22)

9. Jesus YL, Jesus BS, Lopes ET. Nossas identidades e o ensino de Ciências: algumas reflexões. In: Anais VI Fórum Identidade e Alteridades e II Congresso Nacional Educação e Diversidade. UFS, Itabaiana, 2013.

10. Bogdan RC, Biklen SK. Investigação qualitativa em educação. Porto: Porto Editora; 1994.

11. Teles MFS, Souza ACM, Gomberg E. A FUNASA e as visões de mobilização social dos moradores de Mocambo, Sergipe. Rev Saúde Coletiva [internet]. 2010 [citado em 5 jan 2014]; 7(38): 43-49. Disponível em: http://www.redalyc.org/articulo.oa?id=84212375003

12. Souza EC. (Auto)biografia, identidades e alteridade: modos de narração, Escritas de si e Práticas de Formação na Pós-graduação. Ver. Fórum Identidades. 2008; 2(4):37-50.

13. Verrangia D, Silva PBG. Cidadania, relações étnico-raciais e educação: desafios e potencialidade do ensino de Ciências. Rev Educação e Pesquisa. 2010 set./dez. 36(3): 705-718.

14. Jesus, YL.; Brito, M. C. L.; Lopes, E. T. Ciências, Cultura e Educação: Reflexões Acerca do "Eu" e do "Outro". Anais... In: IX Colóquio Internacional "Educação e Contemporaneidade" São Cristóvão - SE, 2015. ISSN: 1982-3657

15. Lopes ET et al. Concepções e Análises de Material Didático na Perspectiva da Diversidade. (Curso de Aperfeiçoamento: Produção de Material Didático para a Diversidade). São Cristóvão - SE; 2012. (Centro de Educação Superior a Distância) Universidade Federal de Sergipe.

16. Lopes, ET; Jesus, YL. (Re/Des) Construção das Visões Acerca dos Indígenas na Formação Docente em Ciências da Natureza. Revista SODEBRAS, v. 10, p. 279-289, 2015. 